\title{
Therapeutic Effects and Molecular Network Mechanism of Chinese herbs for Coronavirus Disease-19
}

\section{Jingjing Da}

Guizhou University https://orcid.org/0000-0002-2856-5041

\section{Xiangyan Zhang}

Guizhou Provincial People's Hospital

\section{Fa Sun}

Guizhou Provincial People's Hospital

Kui Zhang

Guizhou Provincial People's Hospital

Xianchun Zeng

Guizhou Provincial People's Hospital

\section{Rongpin Wang}

Guizhou Provincial People's Hospital

Hourong Zhou

Guizhou Provincial People's Hospital

\section{Weidong Wu}

Guizhou Normal College

Yan Zha ( $\nabla$ yanzhagz@126.com )

Guizhou Provincial People's Hospital

\section{Research}

Keywords: The coronavirus disease-19, integrated traditional Chinese and Western medicine, network pharmacology analysis, Quercetin, Prostaglandin G/H synthase 2

Posted Date: May 22nd, 2020

DOI: https://doi.org/10.21203/rs.3.rs-29056/v1

License: (c) (i) This work is licensed under a Creative Commons Attribution 4.0 International License. Read Full License 


\section{Abstract}

Background: The coronavirus disease-19 (COVID-19) outbreak on December 2019. The present study was aimed to explore the therapeutic effects and the network pharmacology mechanism of Chinese herbs in COVID-19 patients.

Methods: In this retrospective study, demographic, clinical signs, radiography, and laboratory of 78 patients were analysis from patients' medical records. Network pharmacology was applied to characterize the action mechanism of herbs decoction.

Results: Of all patients were imported cases with familial aggregation. Survival analysis showed that the proportion of cough $\left(X^{2}=3.864, P=0.049\right)$ and fever $\left(\chi^{2}=5.549, P=0.018\right)$ in TCM group declined faster than control group. There was a significant radiographic lesions remission difference between groups $\left(\chi^{2}\right.$ $=7.666, P=0.006)$. After adjusted by baseline data, the changes of Lymphocytes, ALT and LDH were greater in TCM group ( $P=0.023,0.005,0.015$, respectively). A total of 1852 ingredients in 13 herbs were obtained, among which, the ingredients-target network included 168 compounds and 189 targets, 38 GO terms and 63 pathways were found in enrichment analysis.

Conclusion: The therapeutic effect of Chinese herbs was amelioration of cough and fever, facilitated the absorption of inflammatory infiltrates seen in the lungs, and increased the number of lymphocytes, protection of liver function via the mechanism of inhibition of coronavirus attack organs and immune cells directly. Molecular mechanisms need to be further validate in vitro and vivo.

\section{Background}

The use of Chinese herbs, traditional Chinese medicine (TCM), emphasizing individuality based on body balance and mind-body interaction, plays an holistic role in the treatment of chronic disease (Liao, Li, Lin, Lin, Chiang, \& Li, 2017). Furthermore, many researches has been shown that TCM can also be successfully used for acute and severe diseases treatment, especially when Western medicine is not very working (Luo, Wang, Hesse-Fong, Lin, \& Yuan, 2019). A retrospective study from the Chinese University of Hong Kong found that an approach of integrated Chinese herbs, which contained kaempferol and quercetin for severe acute respiratory syndrome (SARS) had led to satisfactory clinical outcomes (Lin et al., 2003; Schwarz et al.,2014; Zhang, \& Chen, 2008).

The coronavirus disease-19 (COVID-19) caused by a novel type of beta-coronavirus (2019-nCOV), is an acute infectious disease to which the population is generally susceptible (Zhou et al., 2020; Zhu et al.,2020). A global health emergency has been declared by WHO on January 30, 2020 (Li et al., 2020). To date, more than 1 million new cases of COVID-19 have been confirmed in 205 countries, with a total of 51688 deaths. The epidemiological and clinical characteristics of COVID-19 patients have been described in many articles (Zhu et al.,2020; Li et al., 2020). The current outbreak of COVID-19 is both similar and different from previous outbreaks of SARS and Middle East respiratory syndrome (MERS) (Peeri et al.,2020; Al-Tawfiq, J.A.,2020). However, no effective antiviral drug has been found. The limited available 
knowledge underscores the need for supportive treatment and adjunctive drug therapy that is specific for patients with COVID-19 (Arabi, Fowler, \& Hayden, 2020).

COVID-19 is classed as plague in TCM, of which the pathogenesis is dampness, toxin, stasis and heat obstructing the lun. TCM believes that "healthy Qi is stored in, evil cannot be dried", our team emphasized the treatment principle of "nourishing healthy Qi, dispelling dampness evil". On the basis of the previous research on the effect of Shenqi Bufei Decoction on chronic obstructive pulmonary disease (Zhang, Wu, Zhang, Yang, \& Yang,2017), we formulated a prescription of "Bufei Quwen Decoction"(BFQW) that benefits for strengthening the lung resistance to eliminate 2019-nCOV, and involved 13 commonly Chinese herbs, Codonopsis Pilosula, Adenophprae Ae Radix, Hedysarum Multijugum Maxim, Pogostemon Cablin (Blanco) Benth, Mori Cortex, Trichosanthes Kirilowii Maxim, Alpinia Katsumadai Hayat, Atractylodes Macrocephala Koidz, Cinnamomi Ramulus, Poria Cocos(Schw.) Wolf, Radix Salviae, Forsythiae Fructus, Lonicerae Japonicae Flos.

Therefore, the purpose of this study was to demonstrate the superior ability of those Chinese herbs in exerting therapeutic benefit properties for COVID-19. To this aim, in the present research the clinical characteristics and therapeutic effects of integrated herbs and Western medicine for 78 patients diagnosed with COVID-19 in Guizhou Province have been displayed and the network pharmacology analysis of the herbs prescription was used to explore the molecular mechanism of BFQW in COVID-19 which provide a theoretical basis for clinical practice.

\section{Methods}

\subsection{Herb Preparation and Treatment}

BFQW was designed by our Chinese-herb consulting physician team according to the theory of Chinese medicine and our clinical experience. A total of 13 different kinds of herbs with $5-20 \mathrm{~g}$ of each made up the formula, including 3 monarch herbs, 8 ministerial herbs, and 2 adjuvant herbs were shown in Table 1. Five to 7 packets of BFQW were submerged in cold water $3 \mathrm{~cm}-5 \mathrm{~cm}$ above the surface for 30 minutes, and then put the soaked herbs into the decoction machine (YJD30-GL, DONGHUAYUAN MEDICAL, China) with the water at $110^{\circ} \mathrm{C}$ for $20 \mathrm{~min}$. Decoction was separated $100 \mathrm{ml}$ per sachet after cooling, and stored in refrigerator at $4^{\circ} \mathrm{C}$. The decoction amount of each packet was $300 \mathrm{ml}$, and water loss during processing was $2500 \mathrm{ml}$. So the water amount of decocting herbs was calculated as number of packets $\times 300 \mathrm{ml}+2500 \mathrm{ml}$. The decoction was administered $100 \mathrm{ml}$ each time, three times a day throughout the hospital stay.

\subsection{Patients}

For this retrospective, of the 78 coronavirus disease 2019 (COVID-19) patients diagnosed according to WHO interim guidance were recruited from Jan 20, 2020 to Mar 8, 2020. Eighteen of those patients took BFQW combined with Western medicine as the TCM group versus 60 cases by treatment protocol (trail 
version 7) in the control group (Jin et al., 2020). We obtained demographic, epidemiological, clinical signs and symptoms, laboratory, and outcome data from patients' medical records.

\subsection{Exposure history and clinical classification}

According to WHO Interim Guidance, the case in this study was defined as any one with exposure history and consistent with any two clinical manifestations and the pathogenic evidence (Wu et al.,2020).

Exposure history: (1) Input, within 14 days before the onset of the disease, there were tourism or residence histories of Wuhan or its surrounding areas, or other communities with confirmed cases; (2) Close contacts, within 14 days before the onset of the disease, there were contacts with confirmed cases of COVID-19 or aggregation in an enclosed environment (such as a family house, a construction site, an office, etc.).

Clinical classification: (1) Mild, the clinical symptoms were mild, with no radiographic findings; (2) Moderate, with fever, cough and other respiratory symptoms, imaging findings of pneumonia; (3) Severe, with dyspnea, respiratory frequency $\geq 30 / \mathrm{min}$, blood oxygen saturation $\leq 93 \%$, partial pressure of arterial oxygen to fraction of inspired oxygen ratio $<300$, and/or lung infiltrates $>50 \%$ within 24 to 48 hours.

\subsection{Chest CT Image Analysis}

Two radiologists with 12 and 10 years of experience in interpreting chest CT imaging, respectively, reviewed all chest CT images at admission and discharge and classified the cumulative lesion distribution range as $<10 \%, 10 \%-25 \%, 26 \%-50 \%, 51 \%-75 \%,>75 \%$ for COVID-19 patients. The degree of radiographic lesions remission was expressed by the difference of imaging changes between discharge and admission.

\subsection{Disease-drug-target network construction}

In absorption, distribution, metabolism, and excretion processes, the ingredients that conformed the Lipinski rules with oral bioavailability $(O B) \geq 30 \%$ and drug likeness $(D L)$ index $\geq 0.18$ were selected as active substances in the current study. Bioactive ingredients of BFQW and those potential targets were retrieved from the traditional Chinese medicine systems pharmacology database (http://tcmspw.com/) (Ru et al., 2014). To associate a therapeutic target with COVID-19, we retrieved coronavirus infected disease and acute respiratory distress syndrome(ARDS)-associated therapeutic targets from GeneCards and OMIM database. A drug-targets-disease network was mapped and visualized using Cytoscape 3.6.1 (Shannon et al., 2003).

\subsection{Network analysis}


In these graphical networks, the compounds, proteins, or pathways were expressed as nodes, whereas the compound-target or target-pathway interactions were expressed as edges. Using CentiScaPe 2.2 plug-in of Cytoscape, the critical nodes in the network were filtered by twice the median of degree, closeness and betweenness. ClueGO plug-in of Cytoscape was used to analyze the pathway enrichment of the critical targets of BuFeiQuWen decoction in the treatment of COVID-19.

\subsection{Statistical analysis}

SPSS software (IBM, Chicago, IL) were used for statistical analyses. Means(SDs) were used for normally and non-normally descriptive statistics of continuous variables. The classification variable is presented as a count (\%). Skewed data among the groups were analyzed using Kruskal - Wallis test. Categorical variables were estimated for clinical characteristics by the Linexlist data chi-square test. Survival analysis of cough and fever was performed by the Kaplan-Meier method with Log-rank test. The changes of laboratory indicators were calculated by the difference of these at admission and discharge. In changes analysis, the difference of baseline lymphocytes, alanine aminotransferase (ALT), and lactic dehydrogenase (LDH) were statistically significant between control group and TCM group, therefore the changes adjusted by linear regression analysis using baseline data. Throughout the study, $\mathrm{P}<0.05$ was taken as the minimum level of statistical significance.The relevant datasets were directly uploaded to Mendeley Data (Zha,\& Da, 2020).

\section{Results}

\subsection{Identification of bioactive ingredients in BFQW and targets in COVID-19}

A total of 1852 ingredients in BFQW were obtained from TCMSP database, 236 of which belong to Lonicerae Japonicae Flos, had the most ingredients and a minimum of 34 ingredients to Poria $\operatorname{Cocos}($ Schw) Wolf. Among these ingredients in BFQW, 212 (11.50\%) met the requirements of Lipinski rules, OB 30\% and DL index 0.18 (Table 1). After eliminating the overlaps, 188 ingredients were chosen as candidate active ingredients for further analyses. 
Table 1

Composition of Bu Fei Qu Wen Decoction

\begin{tabular}{|c|c|c|c|c|c|c|}
\hline $\begin{array}{l}\text { Pharmaceutical } \\
\text { Name }\end{array}$ & $\begin{array}{l}\text { Chinese } \\
\text { Name }\end{array}$ & $\begin{array}{l}\text { Principles of } \\
\text { System Theory }\end{array}$ & $\begin{array}{l}\text { Dose } \\
\text { (g) }\end{array}$ & Weight & $\begin{array}{l}\text { Number of } \\
\text { Ingredients }\end{array}$ & $\begin{array}{l}\text { Number of } \\
\text { Active } \\
\text { Ingredients }\end{array}$ \\
\hline Codonopsis pilosula & $\begin{array}{l}\text { Dang } \\
\text { Shen }\end{array}$ & Monarch & 20 & $10.26 \%$ & 134 & 18 \\
\hline $\begin{array}{l}\text { Adenophprae Ae } \\
\text { Radix }\end{array}$ & $\begin{array}{l}\text { Nan } \\
\text { Sha } \\
\text { Shen }\end{array}$ & Monarch & 20 & $10.26 \%$ & 82 & 5 \\
\hline $\begin{array}{l}\text { Hedysarum } \\
\text { Multijugum Maxim }\end{array}$ & $\begin{array}{l}\text { Huang } \\
\text { Qi }\end{array}$ & Monarch & 20 & $10.26 \%$ & 87 & 14 \\
\hline $\begin{array}{l}\text { Pogostemon Cablin } \\
\text { (Blanco) Benth }\end{array}$ & $\begin{array}{l}\text { Huo } \\
\text { Xiang }\end{array}$ & Ministerial & 10 & $5.13 \%$ & 94 & 9 \\
\hline Mori Cortex & $\begin{array}{l}\text { Sang } \\
\text { Bai Pi }\end{array}$ & Ministerial & 20 & $10.26 \%$ & 194 & 27 \\
\hline $\begin{array}{l}\text { Trichosanthes } \\
\text { Kirilowii Maxim }\end{array}$ & Gua Lou & Ministerial & 10 & $5.13 \%$ & 80 & 10 \\
\hline $\begin{array}{l}\text { Alpinia Katsumadai } \\
\text { Hayat }\end{array}$ & $\begin{array}{l}\text { Dou } \\
\text { Kou }\end{array}$ & Ministerial & 10 & $5.13 \%$ & 71 & 12 \\
\hline $\begin{array}{l}\text { Atractylodes } \\
\text { Macrocephala Koidz }\end{array}$ & Bai Zhu & Ministerial & 15 & $7.69 \%$ & 55 & 7 \\
\hline Cinnamomi Ramulus & Gui Zhi & Ministerial & 5 & $2.56 \%$ & 220 & 7 \\
\hline $\begin{array}{l}\text { Poria } \operatorname{Cocos}(\text { Schw.) } \\
\text { Wolf }\end{array}$ & Fu Lin & Ministerial & 15 & $7.69 \%$ & 34 & 13 \\
\hline Radix Salviae & $\begin{array}{l}\text { Dan } \\
\text { Shen }\end{array}$ & Ministerial & 20 & $10.26 \%$ & 202 & 59 \\
\hline Forsythiae Fructus & $\begin{array}{l}\text { Lian } \\
\text { Qiao }\end{array}$ & Adjuvant & 15 & $7.69 \%$ & 150 & 17 \\
\hline $\begin{array}{l}\text { Lonicerae Japonicae } \\
\text { Flos }\end{array}$ & $\begin{array}{l}\text { Jin Yin } \\
\text { Hua }\end{array}$ & Adjuvant & 15 & $7.69 \%$ & 236 & 15 \\
\hline \multicolumn{7}{|c|}{$\begin{array}{l}\text { codonopsis pilosula, adenophprae ae radix, hedysarum multijugum maxim, pogostemon cablin } \\
\text { (blanco) benth, mori cortex, trichosanthes kirilowii maxim, alpinia katsumadai hayat, atractylodes } \\
\text { macrocephala koidz, cinnamomi ramulus, poria } \operatorname{cocos}(\text { schw.) wolf, radix salviae, forsythiae fructus, } \\
\text { lonicerae japonicae flos, }\end{array}$} \\
\hline
\end{tabular}

1703 protein targets were retrieved from TCMSP database among the 188 candidate bioactive components. 3767 coronavirus infected disease and acute respiratory distress syndrome (ARDS) related human genes were collected from GeneCards and OMIM database. Then, these protein targets of BFQW 


\subsection{Demographics and clinical characteristics of patients infected with COVID-19}

Of all the 78 patients without medical staff in Guizhou Province were investigated in this study. 29 cases (37.18\%) had a history of chronic diseases, including 11 cases cardiovascular and cerebrovascular diseases, 4 cases respiratory system diseases, 2 cases diabetes and 12 other malignant tumors or surgery history. Comparison of demographics and clinical characteristics between control group $(n=60)$ and TCM group $(n=18)$ were shown in Table 2 . There were no statistically significant differences in age, gender, exposure history, virus duration and chronic diseases (data was not shown) between two groups. Groups were also similar in antiviral treatment and immune protection therapy. In TCM group, the severity of diseases they were suffered from and the number of oxygen therapy and antibiotic medications they took were greater than those of control group. 
Table 2

Clinical characteristics of Patients with COVID-19

$\begin{array}{lll}\text { Control group } & \text { TCM group } & \text { Statistics } P \\ (n=60) & P\end{array}$

Age, years

\begin{tabular}{lllll} 
Mean(SD) & $32.21(16.53)$ & $39.28(18.17)$ & $t=0.757$ & 0.124 \\
\hline Range & 55 days -78 & $4-67$ & - & - \\
\hline Sex & & & & \\
Female & $32(53.3)$ & $9(50.0)$ & $\chi^{2}=0.062$ & 0.804 \\
Male & $28(46.7)$ & $9(50.0)$ & &
\end{tabular}

Exposure

\begin{tabular}{|c|c|c|c|}
\hline Input & $33(55.0)$ & $10(55.6)$ & $\chi^{2}=0.002$ \\
\hline Close contacts & $27(45.0)$ & $8(44.4)$ & \\
\hline
\end{tabular}

Diagnosis

\begin{tabular}{|llll|}
\hline Mild & $12(20.0)$ & $1(5.6)$ & \multirow{2}{*}{0.002} \\
\cline { 1 - 3 } Moderate & $34(56.7)$ & $12(66.7)$ & \\
\cline { 1 - 3 } Severe & $14(23.3)$ & $5(27.8)$ & \\
\hline
\end{tabular}

Treatment

\begin{tabular}{lllll}
\hline Oxygen therapy & $34(56.7)$ & $17(94.4)$ & $\chi^{2}=8.731$ & 0.003 \\
\hline Antiviral treatment* & $57(95.0)$ & $18(100.0)$ & $\chi^{2}=0.963$ & 0.333 \\
\hline Antibiotic treatment & $6(10.0)$ & $11(61.1)$ & $\chi^{2}=21.22$ & $<0.001$ \\
\hline $\begin{array}{l}\text { Immune protection therapy } \\
\text { Clinical outcome }\end{array}$ & $13(21.7)$ & $4(22.2)$ & $\chi^{2}=0.003$ & 0.960 \\
\hline $\begin{array}{l}\text { Radiographic lesions } \\
\text { remission }\end{array}$ & $23(38.3)$ & $14(77.8)$ & & \\
\hline \begin{tabular}{l} 
Clinical characteristics of Patients with COVID-19 \\
\hline
\end{tabular} & & & & \\
\hline
\end{tabular}

\subsection{Clinical signs and CT findings of patients with COVID-19}

The most common signs were cough, fever, phlegm, digestive symptom, and hypodynamia, which accounted for 46 cases (58.97\%), 36 cases (46.15\%) , 25 cases (32.05\%), 23 cases $(29.49 \%)$ and 15 
cases (19.23\%) in all patients respectively. Except for 6 patients (7.69\%) with liver and digestive injury, there was no other organ damage. The proportion of clinical signs at admission, the fifth day and at discharge, and the scale of pulmonary imaging lesions between control group and TCM group were shown in table 3. Survival analysis showed that the proportion of cough $\left(X^{2}=3.864, P=0.049\right)$ and fever $\left(X^{2}=5.549, P=0.018\right)$ in TCM group declined faster than that of the control group (Figure 1). Of note, hypodynamia in control group increased at day 5 and continued to the end of the hospital stay (Supplement 5).The scale of pulmonary imaging lesions at admission and at discharge were also shown in Supplement 5. There was a significant radiographic lesions remission difference between control group and TCM group ( $X^{2}=7.666, P=0.006$, table 2 ). 
Table 4

Changes of laboratory results in patients with COVID-19

\begin{tabular}{|c|c|c|c|}
\hline & Control group $(n=60)$ & TCM group $(n=18)$ & $P$ value \\
\hline \multicolumn{4}{|c|}{ Leucocytes (×10区/L; normal range 3.5-9.5) } \\
\hline Baseline Mean(SD) & $6.17(1.96)$ & $6.12(2.76)$ & 0.796 \\
\hline Changes(SD) & $-0.45(1.75)$ & $-0.18(3.02)$ & 0.240 \\
\hline \multicolumn{4}{|c|}{ Neutrophils percentage (\%; normal range $40-70)$} \\
\hline Baseline Mean(SD) & $57.81(12.80)$ & $65.23(17.57)$ & 0.092 \\
\hline Changes(SD) & $-1.04(10.82)$ & $-9.56(16.71)$ & 0.110 \\
\hline \multicolumn{4}{|c|}{ Lymphocytes (×10区/L; normal range 1.1-3.2) } \\
\hline Baseline Mean(SD) & $2.01(0.92)$ & $1.44(0.86)$ & 0.019 \\
\hline Adjusted Changes(SD) \& & $0.002(0.127)$ & $0.081(0.119)$ & 0.023 \\
\hline \multicolumn{4}{|c|}{ C-reactive protein (mg/L; normal range $0-5$ ) } \\
\hline Baseline Mean(SD) & 7.32(9.89) & $23.60(37.18)$ & 0.131 \\
\hline Changes(SD) & $-0.45(10.67)$ & $-13.29(41.53)$ & 0.976 \\
\hline \multicolumn{4}{|c|}{ Glucose (mmol/L; normal range 3.9-6.1) } \\
\hline Baseline Mean(SD) & $5.41(1.40)$ & $6.81(4.05)$ & 0.439 \\
\hline Changes(SD) & $0.10(1.29)$ & $-0.69(1.52)$ & 0.374 \\
\hline \multicolumn{4}{|c|}{ Alanine aminotransferase (U/L; normal range 9-50) } \\
\hline Baseline Mean(SD) & 21.75(19.46) & $35.35(22.12)$ & 0.008 \\
\hline Adjusted Changes(SD) ${ }^{\&}$ & $5.86(12.09)$ & $-4.12(15.04)$ & 0.005 \\
\hline \multicolumn{4}{|c|}{ Aspartate aminotransferase (U/L; normal range 15-40) } \\
\hline Baseline Mean(SD) & 27.44(20.02) & 27.00(13.27) & 0.389 \\
\hline Changes(SD) & $-1.92(23.96)$ & $-5.45(5.09)$ & 0.182 \\
\hline \multicolumn{4}{|c|}{ Lactic dehydrogenase (U/L; normal range 120-250) } \\
\hline Baseline Mean(SD) & 191.95(83.80) & 238.53(94.27) & 0.020 \\
\hline Adjusted Changes(SD) \& & $-26.72(72.54)$ & $-69.44(82.58)$ & 0.015 \\
\hline
\end{tabular}




\subsection{Changes of laboratory results in patients with COVID-19}

There were no statistically significant differences of baseline data and changes in leucocytes, percentage of neutrophils, C-reactive protein, glucose, aspartate aminotransferase, but the decreasing trend of these indicators in TCM group was higher than that of control group in table 3. After adjusted by baseline data, the changes of Lymphocytes, ALT and LDH were greater than those of control group $(P=0.023,0.005$, 0.015 , respectively).

\subsection{Ingredients-targets network and analysis}

In our study, the ingredients-target network of BFQW on COVID-19 was constructed (Figure 2A). Six active ingredients and 13 targets were selected with indirect degree greater than 26 in network may explain the important therapeutic effect of BFQW on COVID-19 (Figure 2B). Six active ingredients involved quercetin (MOL000098, degree =133, PubChem CID: 5280459), $\beta$-sitosterol (MOL000358, degree = 91, PubChem CID: 222284), kaempferol (MOL000422, degree = 73, PubChem CID:5280863), luteolin (MOL000006, degree =71, PubChem CID: 5280445), stigmasterol (MOL000449, degree = 27, PubChem CID: 5280794), and 7-0-methylisomucronulatol (MOL000378, degree = 26, PubChem CID: 15689652). Thirteen targets namely, PTGS2 (degree = 57), PTGS1 (degree = 52), NCOA2 (degree = 44), SCN5A (degree= 41), PPARG (degree= 41), ADRB2 (degree =39), AR (degree = 39),SCN5A (degree= 41), PRSS1 (degree =35), CHRM1 (degree =35), CHRM3 (degree =27), CHRM2 (degree =26), and ACHE (degree =26). The high-degree protein targets in network may explain the important therapeutic effect of BFQW on COVID-19.

\subsection{GO and pathway enrichment analysis}

To identify the biological characteristics of putative targets of BFQW on COVID-19 in detail, figure 3 shown the $\mathrm{GO}$ and pathway network for characterization the molecular mechanism conducted by ClueGO (Number of gene $=15$, Min percentage $=6.0 \%$ and Kappa score $\geq 0.4$ ), included $38 \mathrm{GO}$ terms and 63 pathways (Supplement 6). The significantly enriched $\mathrm{GO}$ terms indicated that regulation of integrin binding, signaling receptor activity, circulatory system process in membrane region, and neurotransmitter levels in presynaptic membrane to exert therapeutic effects of BFQW on COVID-19. The pathway in AGERAGE signaling (39.02\%) and IL-17 signaling (31.00\%) exhibited the largest percentage of associated genes among the targets. Immunocell damage and immune inflammation related pathways ( such as $T$ cell receptor signaling, IL-17 signaling, NF-KB signaling, Th17 cell differentiation) were mainly found in the network.

\section{Discussion}

The virulence of 2019-nCoV spreads rapidly, mainly through close contact and respiratory droplets, which are easy to cause outbreaks and epidemics in the population (Al-Tawfiq, 2020). The medical team in Guizhou province insists on adopting the "Four Early" measurements, namely "early detection, early 
isolation, early diagnosis and early treatment", to achieve treatment and contain the outbreak. In our opinion, integrated Chinese and Western medicine can obtain satisfactory therapeutic effect, not to mention the specific treatment for COVID-19 has not yet been developed and more frequentative side effects or adverse events induced by antiviral therapy.

In our study, most patients are imported cases, with familial aggregation as the main transmission dynamics. The proportion of gender was equal and the younger average age that contradicted the findings of studies in Wuhan cases (Chen et al., 2020; Huang et al., 2020). The latter concluded that elderly male were more prone to the 2019-nCOV infection than female. It may be influenced by the transmission dynamics and small sample size. Almost all patients were treated with interferon atomization combined with 1 to 2 antiviral drugs. Compared with control group, TCM group needed more nasal catheter and mask oxygen therapy and moxifloxacin for antibiotic medications was associated with the severity of the disease.

The proportion of clinical signs, cough and fever at admission were lower than those of in Wuhan (Chen et al., 2020), in addition to phlegm, diarrhea and poor appetite (digestive signs), and hypodynamia. Survival analysis showed that BFQW shortening the duration of cough and fever. Moreover, there was no increase of fatigue in the TCM group on the fifth day of hospital stay, indicating that the effect of BFQW was initiated significantly and better at amelioration of disease symptoms via enhancement of muscle strength and facilitated the absorption of inflammatory infiltrates seen in the lungs from radiographic image.

Based on limited knowledge of 2019-nCOV, the invasion of respiratory mucosa and down-regulation of angiotensin converting enzyme 2 (ACE2) expression synchronously initiated the self-injury pattern of lung, liver, kidney, and heart in human body (Hoffmann et al., 2020), then triggers a series of immune responses, inducing cytokine storms and causing changes in immune components such as peripheral blood leukocytes and lymphocytes, especially T cells (Channappanavar et al.,2017; Yao et al., 2020). Our laboratory tests found that patients mainly suffered from lung and liver injuries, no kidney damage according to serum creatinine. In order to eliminate the interference and improve agreements of baseline variation, linear regression were applied to correct the data of indicators changes (Tu, Baelum, \& Gilthorpe, 2005), and found that the lymphocytes were significantly increased and ALT, LDH were decreased by BFQW treatment. In addition, it has been reported that patients with COVID-19 infection elevated glucose and CRP level (Wu et al., 2020), were also observed in our study and only had a downward trend without statistical significance for the therapy of BFQW.

In recent research, it has been reported that TCM enhanced antibody production, maintain the balance between Th1 and Th2/Th17 cells for the prevention of viral pneumonia (Fu et al.,2018). This study has proved that BFQW had a better therapeutic effect in patients with COVID-19. Network pharmacology analysis of BFQW bioactive ingredients-targets-disease was constructed to illustrate the key targets and potential mechanism (Molgora et al.,2018). Six active ingredients and 13 targets were predicted to explain the possible mechanism of BFQW on COVID-19. Cyclooxygenase-2 (COX-2), namely Prostaglandin G/H 
synthase 2 (PTGS2) was the most important targets, and the basic researches had found that activating PTGS2 expression and signal cascades by SARS-CoV nucleocapsid and spike protein resulting in inflammation of the lungs (Zhao, \& lyengar, 2012;Yan et al., 2006). Quercetin, the most powerful ingredients was found to protect T cells via restoring Th17/Treg balance through NF-KB and Toll-like receptor signaling pathway (Liu et al.,2007). Ligands for peroxisome proliferator activated receptor gamma (PPARY) had emerged as potent insulin sensitizers used in the treatment of type 2 diabetes (Wei, Tao, Jiang, Zhou, Zhang, \& Yuan, 2017). According to the analysis results, the main mechanism of BFQW was the inhibition of coronavirus attack organs and immune cells directly, and elimination of the cytokine storm.

Some weaknesses and limitations in the present research should be noted. First of all, retrospective nature limited sample size and severity of illness, the conclusions may be influenced by baseline variability although they have been corrected by linear regression. Secondly, the differentially expressed genes of 2019-nCOV infected human have not been obtained. "Coronavirus infected disease and ARDS" was used as the key words to retrieve the existed target molecules of diseases, which may lack of 2019nCOV specific targets that different from SARS or MERS. Thirdly, since biological characteristics of the new virus have not been fully understood, and the virus nucleic acid tested positive again during followup period in some patients, this study did not include the clinical outcome of the first virus duration.

\section{Conclusion}

In this study, we have found that the therapeutic effect of BFQW was amelioration of cough and fever, facilitated the absorption of inflammatory infiltrates seen in the lungs, and increased the number of lymphocytes, protection of liver function via the mechanism of modulating the body's physiological state, inhibition of coronavirus attack organs and immune cells directly, and elimination of the cytokine storm by six active ingredients, quercetin, $\beta$-sitosterol, kaempferol, luteolin, stigmasterol, and 7-0methylisomucronulatol. Those molecular mechanisms predicted by network pharmacology analysis need to be further explore and validate in vitro and vivo.It is the first study to display the effect of BFQW in the integrated Chinese and Western medicine on COVID-19 and to clarify the network mechanism of its active compounds in those 13 herbs. The current study is valuable and noteworthy in clinical practice.

\section{Abbreviations}

ACE2, angiotensin converting enzyme 2

ADRD, acute respiratory distress syndrome

ALT, alanine aminotransferase

BFQW, Bufei Quwen Decoction

COVID-19, coronavirus disease-19 
COX-2, cyclooxygenase-2

LDH, lactic dehydrogenase

MERS, Middle East respiratory syndrome

PPARY, peroxisome proliferator activated receptor gamma

PTGS2, prostaglandin G/H synthase 2

SARS, severe acute respiratory syndrome

TCM, traditional Chinese medicine

\section{Declarations}

\section{Ethics approval and consent to participate}

The protocol was approved by the Ethics Committee of Guizhou Provincial People's Hospital. Informed consent was obtained from all the enrolled patients before data were collected retrospectively.

\section{Consent for publication}

All authors have read and approved the submission of the manuscript.

\section{Availability of data and materials}

The relevant datasets were directly uploaded to Mendeley Data, "Zha, Yan; Da, Jingjing (2020), "Therapeutic Effects of Traditional Chinese Medicine in Coronavirus Disease-19", Mendeley Data, V1, doi: $10.17632 / 94 \mathrm{mddr} 7 \mathrm{xkf} .1^{\prime \prime}$.

\section{Competing interests}

All authors declare that they have no conflict of interest.

\section{Funding}

This work was supported by the National Natural Science Foundation (81960892; 81160450; 81960139). Guizhou Science and Technology Project (QKHZC[2020]4Y002), the Guiyang Science and Technology Project (ZKXM[2020]4). 


\section{Authors' contribution}

Jingjing Da: Conceptualization, Visualization, Writing- Original draft preparation. Xiangyan Zhang: Methodology, Writing - Review \& Editing, Supervision. Fa Sun: Methodology, Investigation. Kui Zhang: Methodology, Investigation. Hourong Zhou: Data curation, Formal Analysis. Weidong Wu: Visualization, Investigation.Xianchun Zeng and Rongpin Wang: Interpreting Chest CT images. Yan Zha: Project Administration.

\section{Acknowledgements}

This work was supported by the National Natural Science Foundation (81960892; 81160450; 81960139). Guizhou Science and Technology Project (QKHZC[2020]4Y002), the Guiyang Science and Technology Project (ZKXM[2020]4).

\section{Reference}

Al-Tawfiq, J.A.(2020). Asymptomatic coronavirus infection: MERS-CoV and SARS-CoV-2 (COVID-19). Travel Med Infect Dis,27,101608. https://doi.org/ 10.1016/j.tmaid.2020.101608.

Arabi, Y.M., Fowler, R., Hayden, F.G.(2020). Critical care management of adults with community-acquired severe respiratory viral infection. Intensive Care Med,46,315-328. https://doi.org/ 10.1007/s00134-02005943-5.

Channappanavar, R., Perlman, S. (2017). Pathogenic human coronavirus infections: causes and consequences of cytokine storm and immunopathology. Semin Immunopathol,39,529-539. https://doi.org/ 10.1007/s00281-017-0629-X.

Chen, N., Zhou, M., Dong, X., Qu, J., Gong, F., Han, Y., Qiu, Y., Wang, J., Liu, Y., Wei, Y., Xia, J., Yu, T., Zhang, X., Zhang, L.(2020). Epidemiological and clinical characteristics of 99 cases of 2019 novel coronavirus pneumonia in Wuhan, China: a descriptive study. Lancet, 395, 507-513. https://doi.org/ 10.1016/S01406736(20)30211-7.

Fu, Y.J., Yan, Y.Q., Qin, H.Q., Wu, S., Shi, S.S., Zheng, X., Wang, P.C., Chen, X.Y., Tang, X.L., Jiang, Z.Y. (2018).Effects of different principles of Traditional Chinese Medicine treatment on TLR7/NF-kB signaling pathway in influenza virus infected mice. Chin Med,13,42. https://doi.org/ 10.1186/s13020-018-0199-4.

Hoffmann, M., Kleine, W.H., Schroeder, S., Krüger, N., Herrler, T., Erichsen, S., Schiergens, T.S., Herrler, G., Wu, N.H., Nitsche, A., Müller, M.A., Drosten, C., Pöhlmann, S.(2020). SARS-CoV-2 Cell Entry Depends on ACE2 and TMPRSS2 and Is Blocked by a Clinically Proven Protease Inhibitor. Cell,8674,30229-4. https://doi.org/ 10.1016/j.cell.2020.02.052. 
Huang, C.L.,Wang, Y.M.,Li, X.W., Ren, L., Zhao, J., Hu, Y., Zhang, L., Fan, G., Xu, J., Gu, X., Cheng, Z., Yu, T., Xia, J., Wei, Y., Wu, W., Xie, X., Yin, W., Li, H., Liu, M., Xiao, Y., Gao, H., Guo, L., Xie, J., Wang, G., Jiang, R., Gao, Z., Jin, Q., Wang, J., Cao, B.(2020). Clinical features of patients infected with 2019 novel coronavirus in Wuhan, China. Lancet, 2020,395,497-506. https://doi.org/10.1016/S0140-6736(20)30183-5.

Jin, Y.H., Cai, L., Cheng, Z.S., Cheng, H., Deng, T., Fan, Y.P., Fang, C., Huang, D., Huang, L.Q., Huang, Q., Han, Y., Hu, B., Hu, F., Li, B.H., Li, Y.R., Liang, K., Lin, L.K., Luo, L.S., Ma, J., Ma, L.L., Peng, Z.Y., Pan, Y.B., Pan, Z.Y., Ren, X.Q., Sun, H.M., Wang, Y., Wang, Y.Y., Weng, H., Wei, C.J., Wu, D.F., Xia, J., Xiong, Y., Xu, H.B., Yao, X.M., Yuan, Y.F., Ye, T.S., Zhang, X.C., Zhang, Y.W., Zhang, Y.G., Zhang, H.M., Zhao, Y., Zhao, M.J., Zi, H., Zeng, X.T., Wang, Y.Y., Wang, X.H., for the Zhongnan Hospital of Wuhan University Novel Coronavirus Management and Research Team.(2020).Evidence-Based Medicine Chapter of China International Exchange and Promotive Association for Medical and Health Care (CPAM).A rapid advice guideline for the diagnosis and treatment of 2019 novel coronavirus (2019-nCoV) infected pneumonia (standard version). Mil Med Res,7,4. https://doi.org/ 10.1186/s40779-020-0233-6.

Li, Q., Guan, X., Wu, P., Wang, X., Zhou, L., Tong, Y., Ren, R., Leung, K.S.M., Lau, E.H.Y., Wong, J.Y., Xing, X., Xiang, N., Wu, Y., Li, C., Chen, Q., Li, D., Liu, T., Zhao, J., Li, M., Tu, W., Chen, C., Jin, L., Yang, R., Wang, Q., Zhou, S., Wang, R., Liu, H., Luo, Y., Liu, Y., Shao, G., Li, H., Tao, Z., Yang, Y., Deng, Z., Liu, B., Ma, Z., Zhang, Y., Shi, G., Lam, T.T.Y., Wu, J.T.K., Gao, G.F., Cowling B.J., Yang, B., Leung, G.M., Feng, Z.(2020). Early Transmission Dynamics in Wuhan, China, of Novel Coronavirus-Infected Pneumonia. N Engl J Med,382,1199-1207. https://doi.org/ 10.1056/NEJMoa2001316.

Liao, Y.H., Li, C.I., Lin, C.C., Lin, J.G., Chiang, J.H., Li, T.C.(2017). Traditional Chinese medicine as adjunctive therapy improves the long-term survival of lung cancer patients. J Cancer Res Clin Oncol, 143,2425-2435. https://doi.org/ 10.1007/s00432-017-2491-6.

Lin, L., Xu, Y.J., He, D.P., Han, Y., Tang, G.H., Yang, Z.M., Yu, H., Lin, Z.X.(2003). A retrospective study on clinical features of and treatment methods for 77 severe cases of SARS.Am J Chin Med, 31, 821839.https://doi.org/ 10.1142/S0192415X03001521.

Liu, M., Yang, Y., Gu, C., Yue, Y., Wu, K.K., Wu, J., Zhu, Y.(2007). Spike protein of SARS-CoV stimulates cyclooxygenase-2 expression via both calcium-dependent and calcium-independent protein kinase $C$ pathways. FASEB J, 21,1586-1596. https://doi.org/ 10.1096/fj.06-6589com.

Luo, Y., Wang, C.Z., Hesse, F.J., Lin, J.G., Yuan, C.S.(2019). Application of Chinese Medicine in Acute and Critical Medical Conditions. Am J Chin Med, 47,1223-1235. https://doi.org/ 10.1142/S0192415X19500629.

Molgora, M., Supino, D., Mavilio, D., Santoni, A., Moretta, L., Mantovani, A., Garlanda, C. (2018). The yinyang of the interaction between myelomonocytic cells and NK cells.Scand J Immunol, 88,e12705. https://doi.org/ 10.1111/sji.12705. 
Peeri, N.C., Shrestha, N., Rahman, M.S., Zaki, R., Tan, Z., Bibi, S., Baghbanzadeh, M., Aghamohammadi, N., Zhang, W., Haque, U. (2020). The SARS, MERS and novel coronavirus (COVID-19) epidemics, the newest and biggest global health threats: what lessons have we learned? Int J Epidemiol, dyaa033. https://doi.org/ 10.1093/ije/dyaa033.

Ru, J.L., Li, P., Wang, J.A., Zhou, W., Li, B.H., Huang, C., Li, P.D., Guo, Z.H., Tao, W.Y., Yang, Y.F., Xu, X., Li, Y., Wang, Y.H., Yang, L.(2014). TCMSP: a database of systems pharmacology for drug discovery from herbal medicines. J Cheminformatics,6,13. https://doi.org/ 10.1186/1758-2946-6-13.

Schwarz, S., Sauter, D., Wang, K., Zhang, R., Sun, B., Karioti, A., Bilia, A.R., Efferth, T., Schwarz, W. (2014). Kaempferol derivatives as antiviral drugs against the $3 a$ channel protein of coronavirus.Planta Med,80,177-182. https://doi.org/ 10.1055/s-0033-1360277.

Shannon, P., Markiel, A., Ozier, O., Baliga, N.S., Wang, J.T., Ramage, D., Amin, N., Schwikowski, B., Ideker, T. (2003). Cytoscape: a software environment for integrated models of biomolecular interaction networks. Genome Research,13,2498-504. https://doi.org/ 10.1101/gr.1239303.

Tu, Y.K., Baelum, V., Gilthorpe, M.S.(2005). The relationship between baseline value and its change: problems in categorization and the proposal of a new method.Eur J Oral Sci, 113, 279-288. https://doi.org/ 10.1111/j.1600-0722.2005.00229.x.

Wang, Q., Imam, M.U., Yida, Z., Wang, F. (2017). Peroxisome Proliferator-Activated Receptor Gamma (PPARY) as a Target for Concurrent Management of Diabetes and Obesity-Related Cancer. Curr Pharm Des, 23, 3677-3688. https://doi.org/ 10.2174/1381612823666170704125104.

Wei, C.B., Tao, K., Jiang, R., Zhou, L.D., Zhang, Q.H., Yuan, C.S.(2017). Quercetin protects mouse liver against triptolide-induced hepatic injury by restoring Th17/Treg balance through Tim-3 and TLR4-MyD88NF-KB pathway. Int Immunopharmacol,53,73-82. https://doi.org/ 10.1016/j.intimp.2017.09.026.

Wu, J., Liu, J., Zhao, X., Liu, C., Wang, W., Wang, D., Xu, W., Zhang, C., Yu, J., Jiang, B., Cao, H., Li, L.(2020). Clinical Characteristics of Imported Cases of COVID-19 in Jiangsu Province: A Multicenter Descriptive Study. Clin Infect Dis, ciaa199. https://doi.org/ 10.1093/cid/ciaa199.

Yan, X., Hao, Q., Mu, Y., Timani, K.A., Ye, L., Zhu, Y., Wu, J.(2006). Nucleocapsid protein of SARS-CoV activates the expression of cyclooxygenase-2 by binding directly to regulatory elements for nuclear factorkappa B and CCAAT/enhancer binding protein.Int J Biochem Cell Biol, 38,1417-1428. https://doi.org/ 10.1016/j.biocel.2006.02.003.

Yao, X., Ye, F., Zhang, M., Cui, C., Huang, B., Niu, P., Liu, X., Zhao, L., Dong, E., Song, C., Zhan, S., Lu, R., Li, H., Tan, W., Liu, D. (2020). In Vitro Antiviral Activity and Projection of Optimized Dosing Design of Hydroxychloroquine for the Treatment of Severe Acute Respiratory Syndrome Coronavirus 2 (SARS-CoV2). Clin Infect Dis, ciaa237. https://doi.org/ 10.1093/cid/ciaa237. [Epub ahead of print] 
Zha, Y., Da, J.J.(2020). Therapeutic Effects of Traditional Chinese Medicine in Coronavirus Disease-19, Mendeley Data, V1, https://doi.org/ 10.17632/94mddr7xkf.1.

Zhang, K., Wu, G.Y., Zhang, X.Y., Yang, P., Yang, Z.(2017). Chinese medicine ShenqiBufei attenuates chronic obstructive pulmonary disease.Int J Clin Exp Med,10,1661-1669.

Zhang, T., Chen, D. (2008). Anticomplementary principles of a Chinese multiherb remedy for the treatment and prevention of SARS. J Ethnopharmacol,117,351-361. https://doi.org/ 10.1016/j.jep.2008.02.012.

Zhao, S., lyengar, R.(2012). Systems pharmacology: network analysis to identify multiscale mechanisms of drug action. Annu Rev Pharmacol Toxicol,52,505-521. https://doi.org/ 10.1146/annurev-pharmtox010611-134520.

Zhou, P., Yang, X.L., Wang, X.G., Hu, B., Zhang, L., Zhang, W., Si, H.R., Zhu, Y., Li, B., Huang, C.L., Chen, H.D., Chen, J., Luo, Y., Guo, H., Jiang, R.D., Liu, M.Q., Chen, Y., Shen, X.R., Wang, X., Zheng, X.S., Zhao, K., Chen, Q.J., Deng, F., Liu, L.L., Yan, B., Zhan, F.X., Wang, Y.Y., Xiao, G.F., Shi, Z.L. (2020). A pneumonia outbreak associated with a new coronavirus of probable bat origin. Nature, 579, 270-273. https://doi.org/10.1038/s41586-020-2012-7.

Zhu, N., Zhang, D., Wang, W., Li, X., Yang, B., Song, J., Zhao, X., Huang, B., Shi, W., Lu, R., Niu, P., Zhan, F., Ma, X., Wang, D., Xu, W., Wu, G., Gao, G.F., Tan, W.; China Novel Coronavirus Investigating and Research Team. (2020). A Novel Coronavirus from Patients with Pneumonia in China, 2019.N Engl J Med, 382, 727733. https://doi.org/10.1056/NEJMoa2001017.

\section{Figures}



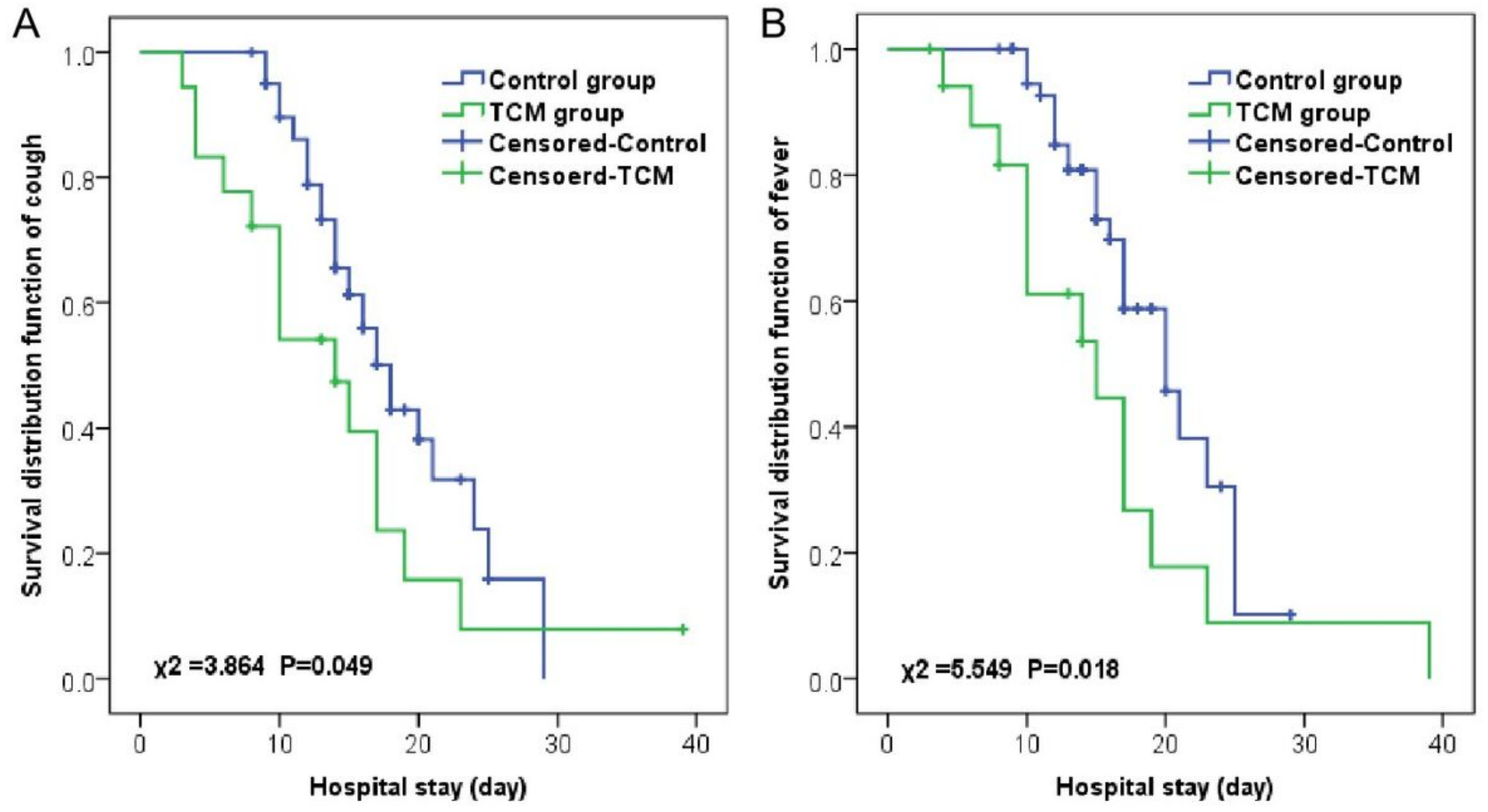

Figure 1

Survival analysis of cough and fever . (A) for cough $\chi 2=3.864, P=0.049 ;(B)$ for fever $\chi 2=5.549, P=0.018$

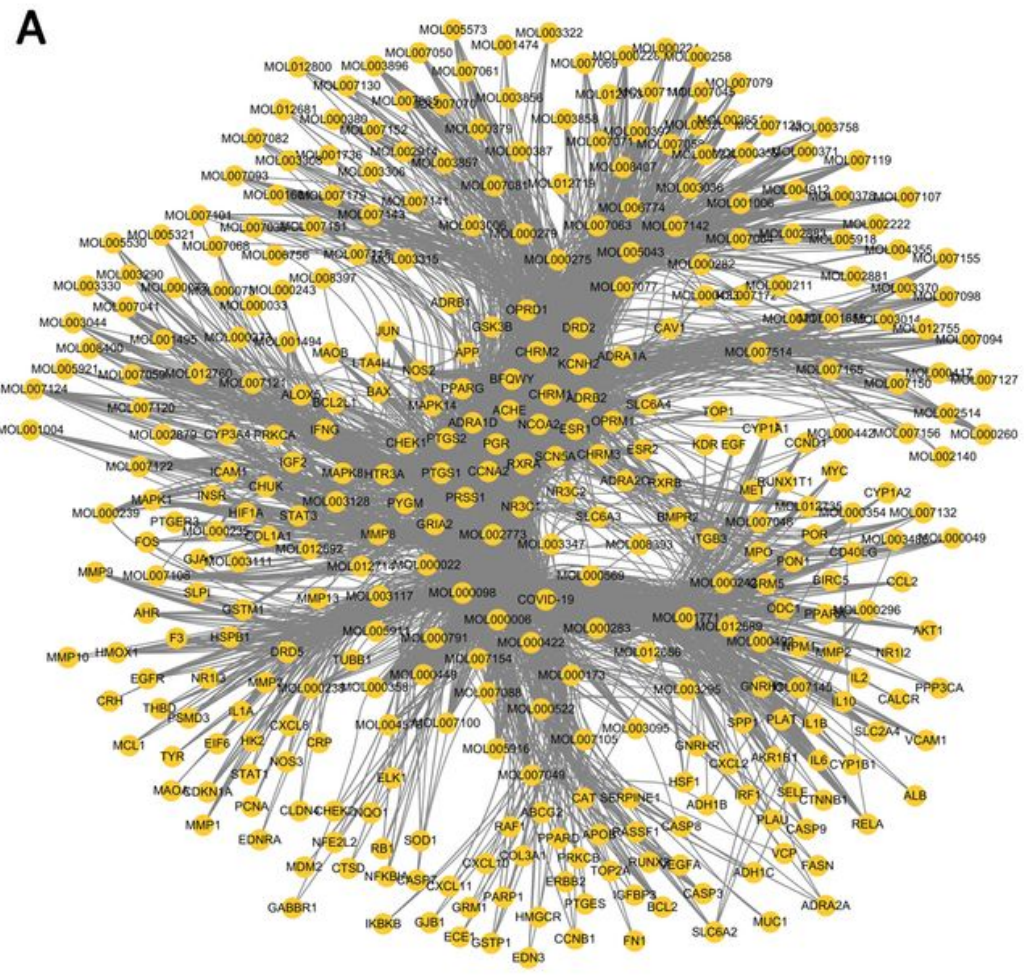

B

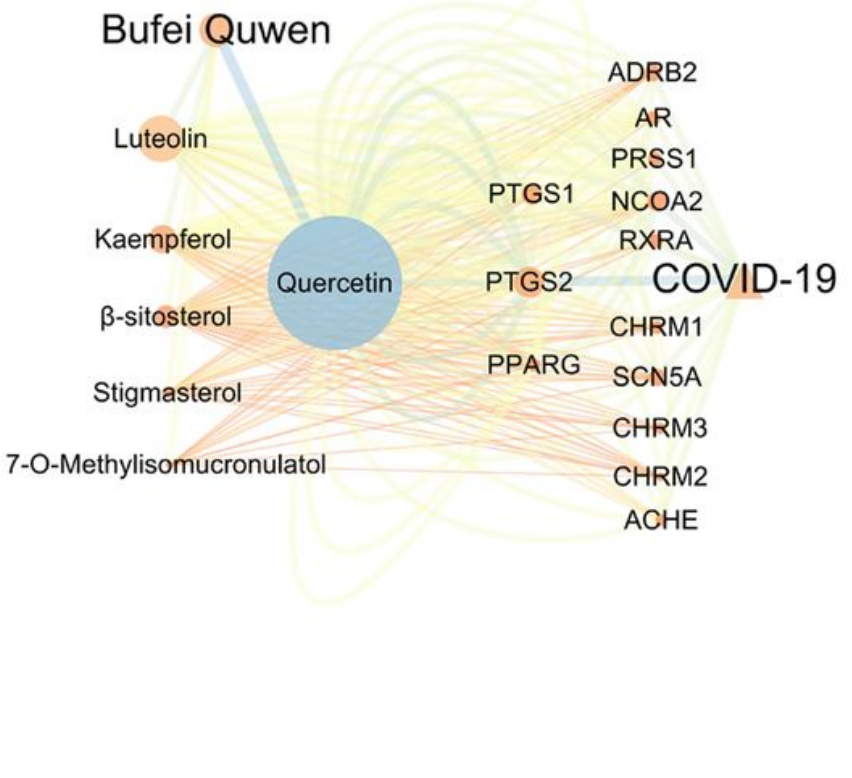


Figure 2

Ingredients-target network of Bufei Quwen Decoction. (A) 189 targets of 168 ingredients were constructed for the network. The orange nodes represent candidate active compounds and potential protein targets. The edges represent the interactions between them and node size is proportional to their degree.(B) Six active ingredients and 13 targets were selected with undirected degree greater than 26 in network

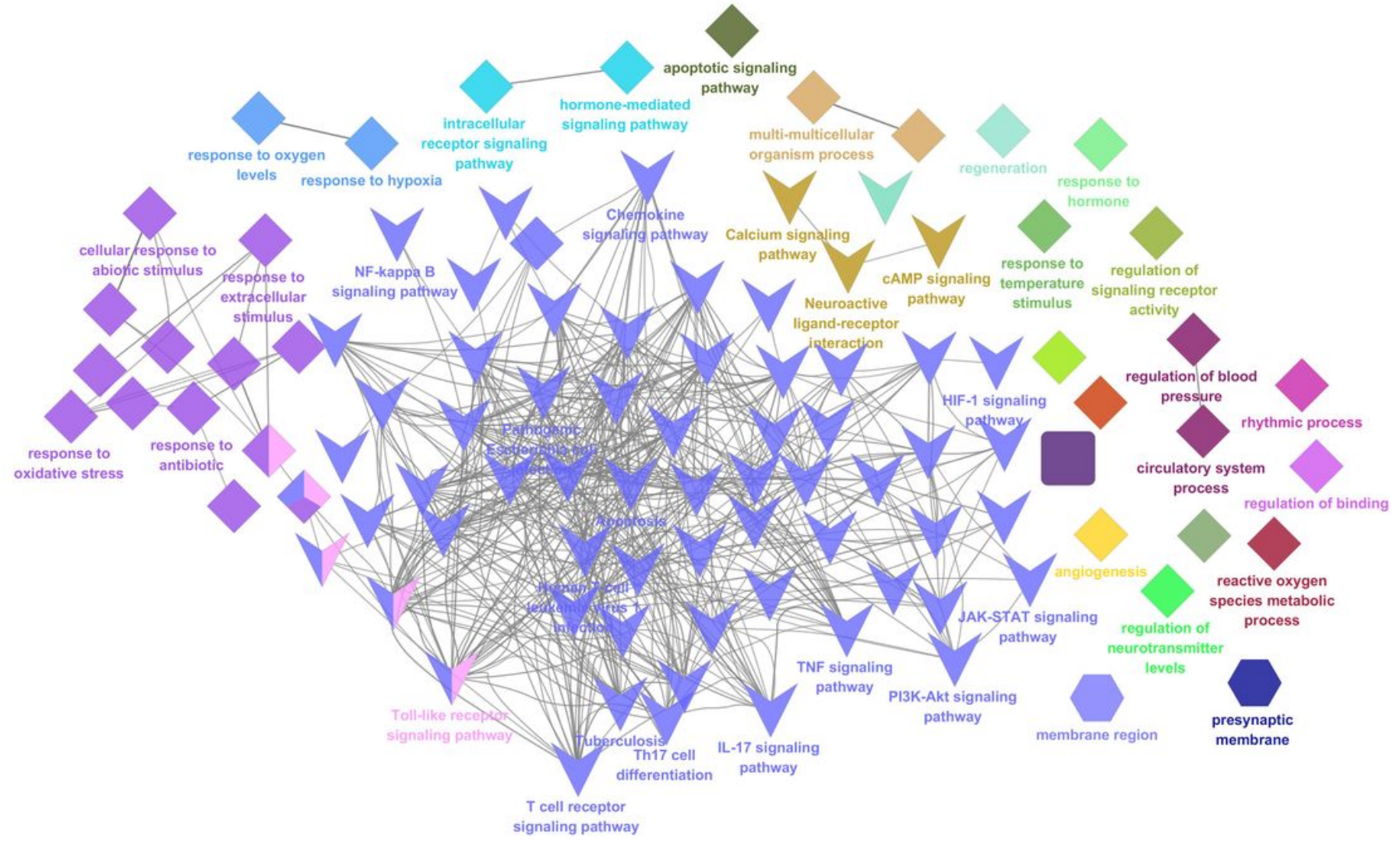

Figure 3

Results of signal pathway analysis of Bufei Quwen Decoction in treatment of COVID-19. The diamond nodes represent biological process, the hexagon nodes represent cellular component targets and the rectangle nodes represent molecular function from $\mathrm{GO}$ analysis. The triangle nodes represent pathways from KEGG analysis. The edges represent the interactions between them

\section{Supplementary Files}

This is a list of supplementary files associated with this preprint. Click to download.

- supplementaryfiles.rar 